\title{
Does coexistence of fragmented QRS and cardiovascular disease have the ability to predict the mortality in hospitalized, critically ill patients with COVID-19?
}

\author{
Fahrettin Katkat* (D), Muhsin Kalyoncuoğlu1 (D), Serkan Karahan* (D), Hanife Abanus* (D),

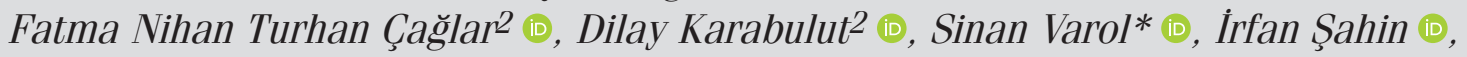 \\ Kerem Erkalp** (i), Ertuğrul Okuyan* (1)
}

Departments of *Cardiology, and **Anaesthesiology, Division of Critical Care, University of Health Sciences, Bağcllar Training and Research Hospital; İstanbul-Turkey

${ }^{1}$ Department of Cardiology, University of Health Sciences, Haseki Training and Research Hospital; İstanbul-Turkey ${ }^{2}$ Department of Cardiology, University of Health Sciences, Bakırköy Sadi Konuk Training and Research Hospital; İstanbul-Turkey

\section{ABSTRACT}

Objective: In this study, we aimed to investigate the prognostic accuracy of the presence of fragmented QRS (fQRS) on baseline electrocardiogram on the adverse outcome in critical patients with coronavirus disease 2019 (COVID-19) with cardiovascular disease (CVD).

Methods: The current study was retrospective designed and included 169 patients who were critically ill with COVID-19 and CVD (mean age of $62 \pm 15$ years). The patients were grouped into those who died (non-survivor group) and those who survived (survivor group).

Results: The non-survivors were older and more often had CVD ( $p=0.009)$, hypertension $(p=0.046)$, diabetes $(p=0.048)$, cancer $(p=0.023)$, and chronic renal failure $(p=0.001)$. Although the presence of fQRS on the basal electrocardiogram was more common in patients who died, this was not statistically significant $(p=0.059)$. Furthermore, non-survivors had more frequent the coexistence of CVD and fQRS ( $p=0.029)$. In Model 1 multivariate regression analysis, CVD alone was not a predictor of mortality $(p=0.078)$, whereas coexistence of CVD and fQRS was found to be an independent predictor of mortality in Model 2 analysis [hazard ratio (HR): 2.243; $p=0.003$ ]. Furthermore, older age (HR: $1.022 ; p=0.006$ and HR: $1.023 ; p=0.005$ ), cancer (HR: 1.912; $p=0.021$ and HR: 1.858; $p=0.031$ ), high SOFA score (HR: $1.177 ; p=0.003$ and HR: $1.215 ; p<0.001$ ), and increased CRP level (HR: 1.003; $\mathrm{p}=0.039$ and HR: 1.003; $\mathrm{p}=0.027$ ) independently predicted the mortality in both multivariate analysis models, respectively.

Conclusion: fQRS may be a useful and handy risk-stratification tool for clinical outcomes by identifying high-risk individuals, especially among those with CVD.

Keywords: coronavirus 2019, fragmented QRS, cardiovascular disease, mortality

Cite this article as: Katkat $F$, Kalyoncuoğlu M, Karahan S, Abanus $H$, Turhan Çağlar FN, Karabulut D, et al. Does coexistence of fragmented QRS and cardiovascular disease have the ability to predict the mortality in hospitalized, critically ill patients with COVID-19?. Anatol J Cardiol 2021: 25; 803-10.

\section{Introduction}

In December 2019, a novel human coronavirus causing respiratory infections was first detected in a series of unexplained pneumonia cases in the Chinese city of Wuhan, subsequently spreading quickly around the world in the first quarter of 2020 (1). The virus leading to the disease named coronavirus disease 2019 (COVID-19) by the World Health Organization was first isolated on January 7, 2020, and labelled the "2019 new coronavirus/severe acute respiratory syndrome coronavirus-2 (2019-nCoV/SARS-CoV-2)" $(2,3)$. In the report prepared by the China Center for Disease Control and Protection, the overall average mortality rate was reported to be $2.3 \%$; however, as mortality increased with age, the report cautioned that rates could be as high as $8 \%$ for those aged 70 to 79 years and $14.8 \%$ for those older than 80 years (4). Moreover, the same report pointed that those with previous concomitant diseases were more likely to get COVID-19 and experience mortality rates

Address for Correspondence: Dr. Fahrettin Katkat, Sağlık Bilimleri Üniversitesi,

Bağcılar Eğitim ve Araştırma Hastanesi, Kardiyoloji Kliniği, İstanbul-Türkiye

Phone: +90 5327110147 E-mail: fahrettin_katkat@hotmail.com

Accepted Date: 07.05.2021 Available Online Date: 21.10.2021

(C) Copyright 2021 by Turkish Society of Cardiology - Available online at www.anatoljcardiol.com DOI:10.5152/AnatolJCardiol.2021.13611 


\section{HIGHLIGHTS}

- Both fragmented QRS (fQRS) and cardiovascular disease (CVD) alone are not significantly associated with mortality, but the coexistence of both is an independent predictor of mortality.

- Myocardial injury is associated with fatal outcome in patients with coronavirus disease 2019 infection. Myocardial injury was more common in patients with CVD and fQRS.

- fORS can be considered as a risk tool that can help improve prognosis and clinical outcomes by identifying high-risk individuals, especially in CVD cases.

higher than that of the general population, including $10.5 \%$ in patients with cardiovascular disease (CVD), 7.3\% in patients with diabetes, $6.3 \%$ in patients with chronic lung disease, $6 \%$ in patients with hypertension, and $5.6 \%$ in patients with active or recent cancer (4). Many recent studies have suggested that CVD in particular is a risk factor for experiencing a more severe COVID-19 disease course. The China Disease Control and Prevention Center reported that a mortality rate of $10.5 \%$ existed among those with comorbid CVD disease compared with the overall case fatality rate of $2.4 \%(5)$.

Fragmented QRS (fQRS) is a novel marker of ventricular depolarization abnormalities that can occur owing to any condition (e.g., ischemia, scar, fibrosis, myofiber disarray, inflammation, and microvascular abnormality) interfering with the normally homogeneous depolarization process within the myocardium and leading to local conduction slowing $(6,7)$. The presence of fORS has been linked to adverse outcomes in patients with various CVDs (7-10). In addition, hypertensive patients with left ventricular hypertrophy showed a significantly greater frequency of fQRS than those without left ventricular hypertrophy (11). Moreover, subclinical left ventricular dysfunction assessed by echocardiography has been proposed to be associated with fQRS in patients with type 2 diabetes (7).

Recently compiled anecdotal evidence suggests that CVD and associated risk factors (e.g., age, hypertension, hyperlipidemia, and diabetes) are more common in patients admitted to the intensive care unit (ICU) with COVID-19 of critical severity. It has also been reported that there is a relationship between the severity of COVID-19 and the presence of CVD and associated risk factors, such as hypertension and diabetes (12). To the best of our knowledge, no study has yet evaluated the relationship between the presence of fORS on baseline electrocardiogram and adverse outcomes in critically ill patients with COVID-19 and CVD. In this study, we aimed to investigate the predictive accuracy of fQRS in determining the rate of in-hospital mortality among these individuals.

\section{Methods}

\section{Study design and participants}

This single-center and observational study included the critically ill patients with COVID-19 patients who were admitted to our hospital between March and May 2020. The medical records of the patients were retrospectively reviewed and analyzed from our patient records database. Baseline clinical and demographic characteristics of patients were collected on admission and during hospitalization by attending physicians. All the data were independently reviewed and entered into a computer database by a trained team of physicians blinded to the details of this study. The study population was divided into 2 groups, those who did not survive (non-survivor group) and those who did (survivor group), and all the data were analyzed. As our study was retrospectively designed, written informed consent from the participants could not be obtained; however, the study protocol conformed to the principles of the Declaration of Helsinki and was approved by the Local Ethics Committee (decision number: 2020.05.2.13.069).

A total of 1,126 records of patients with COVID-19 were retrospectively reviewed and analyzed for possible inclusion. Of these, 940 patients were not critically ill, and 186 had presented with a critical severity of COVID-19. Of these 186 critical patients, those with a permanent pacemaker $(n=3)$, those with complete bundle-branch block (BBB) $(n=8)$, those referred to another center $(n=4)$, and those with any missing information $(n=2)$ were excluded from this study. Finally, a total of 169 patients admitted to the intensive care unit constituted the study population.

\section{Electrocardiography}

A standard 12-lead electrocardiogram recording was obtained at a paper speed of $25 \mathrm{~mm} / \mathrm{sec}$, an amplification of 1 $\mathrm{mV}$, and a filter range of 0.1 to $150 \mathrm{~Hz}$ and analyzed by 2 experienced, independent cardiologists who were blinded to details of the study population.

fQRS was defined by a presence of $R^{\prime}$, notching of the R-wave, notching of the downstroke or upstroke of the S-wave, or the presence of more than one $R^{\prime}$ (fragmentation) in 2 contiguous leads (Fig. 1). A typical BBB pattern (QRS $\geq 120 \mathrm{~ms}$ ) and incomplete right $\mathrm{BBB}$ were excluded from the original definition. The presence of 2 or more fQRS complexes was considered to suggest fQRS, whereas the presence of only one fQRS complex was not considered to indicate fragmentation (8).

\section{Definitions and study endpoint}

CVD was defined as any cardiovascular pathology including coronary heart disease, cerebrovascular disease (stroke), peripheral vascular disease, heart failure, rheumatic heart disease, congenital heart disease, and cardiomyopathies $(13,14)$. The diagnosis of severe COVID-19 was made according to the guidelines for the diagnosis and treatment of COVID19 (trial seventh edition) published by the Chinese National Health 


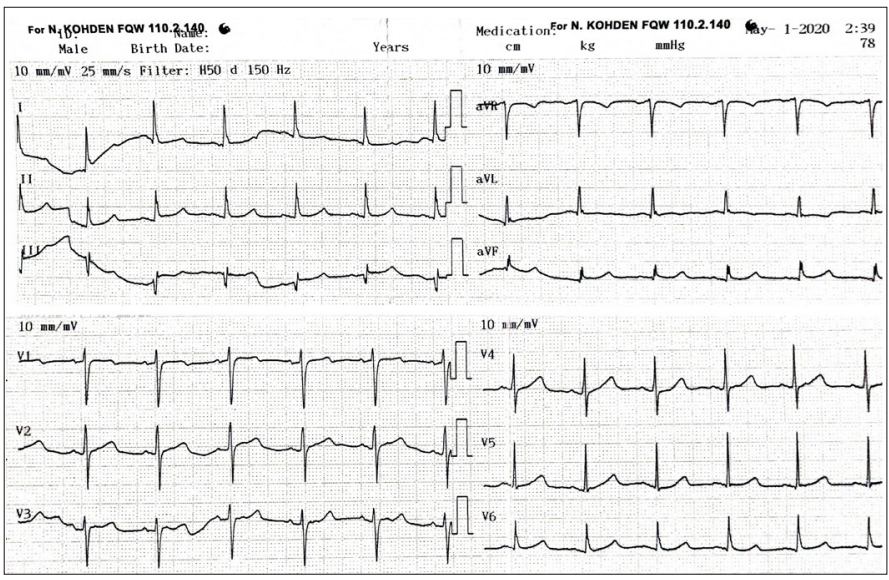

Figure 1. Electrocardiogram sample of a patient with fQRS in the inferior and lateral leads (DII-III, aVF, DI, and aVL)

Commission on March 03, 2020. Critical disease was defined as the presence of any of the following criteria; respiratory failure requiring mechanical ventilation, shock, or other organ failure requiring ICU care (15).

In terms of COVID-19-related complications, acute respiratory distress syndrome (ARDS) was diagnosed according to the guidance of the World Health Organization released for COVID19 (16). Myocardial injury was confirmed when the blood level of the cardiac biomarker cardiac troponin I (cTnl) increased above the $99^{\text {th }}$ percentile upper-reference limit, in accordance with the Fourth Universal Definition of Myocardial Infarction (17). Malignant arrhythmia was defined as a rapid ventricular tachycardia lasting more than 30 seconds that induced hemodynamic instability and/or ventricular fibrillation (18). Acute kidney injury was defined according to the 2012 Kidney Disease: Improving Global Outcomes Clinical Practice Guidelines (19). Shock was defined as the acute onset of new and sustained hypotension (mean arterial pressure $<65 \mathrm{mmHg}$ or systolic blood pressure $<90 \mathrm{~mm} \mathrm{Hg}$ ) accompanied by signs of hypoperfusion requiring intravenous fluid or vasopressors to maintain adequate blood pressure (16). The sequential organ failure assessment (SOFA) score was calculated using the downloaded version from www. $\mathrm{mdcalc.com/sequential-organ-failure-assessment-sofa-score.}$

The primary endpoint of this study was COVID-19 associated in-hospital mortality during the follow-up period. The national death notification system and hospital records were used to obtain information on mortality.

\section{Statistical analysis}

Continuous variables were presented as mean \pm standard deviation (if normal distribution) and median (interquartile range) (if non-normal distribution). Categorical variables were presented as percentages. The chi-squared $\left(\chi^{2}\right)$ test was used to compare categorical variables between the groups. The KolmogorovSmirnov test was used to assess whether the variables were normally distributed. The Student's t-test or Mann-Whitney U test was used to compare the continuous variables between the groups according to whether they were normally distributed or not. To identify the independent predictors of in-hospital mortality, univariate and multivariate Cox regression analyses were performed; notably, only the variables with a $p$-value $<0.1$ in the univariate analysis were incorporated into the multivariate analysis with the results reported as the hazard ratios (HR) and $95 \%$ confidence intervals (CI). Survival assessments for patients with coexisting CVD and fQRS were determined by using Kaplan-Meier analysis and the log rank test. The threshold of statistical significance was established at $p<0.05$. Statistical analyses were performed using the Statistical Package for the Social Sciences version 24.0 software program (IBM Corp., Armonk, NY, USA).

\section{Results}

The study population included 169 critically ill patients with COVID-19 with a mean age of $62 \pm 15$ years. Of these, 104 (61.5\%) were men, and the median time from admission to the end of follow-up was 13 days. During the follow up period, in-hospital mortality was observed in $112(66.3 \%)$ patients. Compared with the survivors, those who died were typically older $(53 \pm 13$ vs. $66 \pm 14$ years; $p<0.001)$. In terms of the most common main comorbidities, CVD ( $n=44,39.3 \%$ vs. $n=11,19.3 \%$; $p<0.009$ ), hypertension $(n=47,42 \%$ vs. $n=15,26.3 \% ; p=0.046)$, diabetes $(n=38,33.9 \%$ vs. $n=11,19.3 \%, p=0.048)$, cancer $(n=17,15.2 \%$ vs. $n=2,3.5 \%$; $\mathrm{p}=0.023$ ), and chronic renal failure (CRF) ( $n=32,28.6 \%$ vs. $n=4$, $7 \% ; p=0.001$ ) were significantly more common among the nonsurvivors than those who survived. Although the presence of fQRS on the basal electrocardiogram was more common in patients who died, this was not statistically significant $(p=0.059)$. The coexistence of CVD and fQRS was significantly more common in non-survivors ( $n=25,22.3 \%$ vs. $n=5,8.8 \% ; p=0.029$ ). Nonsurvivors also presented a higher SOFA score ( $5.9 \pm 1.8$ vs. $4.0 \pm 0.9$ points; $p<0.001$ ).

In terms of the complications associated with COVID, requiring invasive mechanical ventilation, ARDS, myocardial injury, malignant ventricular arrhythmia, acute kidney injury, and shock were also more frequent among non-survivors ( $p<0.05$ for all). In addition, patients with fORS ( $\mathrm{n}=34,55.7 \%$ ) more often experienced myocardial injury than those without fQRS $(p=0.034)$, and myocardial injury was observed more frequently among patients with CVD and fQRS $(n=21 ; 70 \%)$ than those without either $(p=0.002)$.

When the groups were considered in terms of laboratory parameters, the patients who died had higher $\mathrm{C}$-reactive protein (CRP) $(p=0.006)$ on admission, peak $D$-dimer $(p<0.001)$, peak CK-MB $(p<0.001)$, and peak hs-Tnl levels $(p=0.019)$; lower levels of hemoglobin $(p=0.015)$ and albumin $(p<0.001)$; and a lower estimated glomerular filtration rate $(p<0.001)$. In addition, higher neutrophil counts and lower lymphocyte counts were also observed in non-survivors ( $p=0.039$ and $p<0.001$, respectively). Detailed demographic, clinical, and laboratory characteristics of the study population are summarized in Tables 1 and 2 . 


\begin{tabular}{|c|c|c|c|c|}
\hline Variables & All population (n=169) & Survivors ( $n=57$ ) & Non-survivors (n=112) & $P$-value \\
\hline Male sex, n (\%) & $104(61.5)$ & $32(56.1)$ & $72(64.3)$ & 0.303 \\
\hline Body mass index $\left(\mathrm{kg} / \mathrm{m}^{2}\right)$ & $26.1 \pm 2.6$ & $25.7 \pm 2.8$ & $26.3 \pm 2.4$ & 0.165 \\
\hline CVD, n (\%) & $55(32.3)$ & $11(19.3)$ & $44(39.3)$ & 0.009 \\
\hline Diabetes mellitus, $\mathrm{n}(\%)$ & $49(29)$ & $11(19.3)$ & 38 (33.9) & 0.048 \\
\hline Currently smoking, n (\%) & $77(45.6)$ & $23(40.4)$ & $54(48.2)$ & 0.332 \\
\hline COPD & $38(22.9)$ & $9(15.8)$ & $29(25.9)$ & 0.137 \\
\hline Cancer & $19(11.2)$ & $2(3.5)$ & $17(15.2)$ & 0.023 \\
\hline Fragmented QRS, n (\%) & $61(36.1)$ & $15(26.3)$ & $46(41.1)$ & 0.059 \\
\hline CVD+fragmented QRS, n (\%) & $30(17.8)$ & $5(8.8)$ & $25(22.3)$ & 0.029 \\
\hline SOFA score & $5.2 \pm 1.8$ & $4 \pm 0.9$ & $5.9 \pm 1.8$ & $<0.001$ \\
\hline Invasive mechanical ventilation & $136(80.5)$ & $29(50.9)$ & $107(95.5)$ & $<0.001$ \\
\hline ARDS & $100(83.9)$ & $13(22.8)$ & $87(77.7)$ & $<0.001$ \\
\hline Myocardial injury & $76(45)$ & $14(24.6)$ & $62(55.4)$ & $<0.001$ \\
\hline Malign ventricular arrhythmia & $6(3.6)$ & $1(1.8)$ & $5(4.5)$ & 0.037 \\
\hline Acute kidney injury & $35(20.7)$ & $5(8.8)$ & $31(28.2)$ & 0.004 \\
\hline Tocilizumab & $25(14.8)$ & $7(12.3)$ & $18(16.1)$ & 0.506 \\
\hline Length of ICU stay in days, median, (IQR) & $8(3-12)$ & $4(1-8)$ & $9(6-14)$ & $<0.001$ \\
\hline $\begin{array}{l}\text { Length of hospital stay in days, median, } \\
\text { (IOR) }\end{array}$ & $13(9-18)$ & $13(10-19)$ & $13(9-17)$ & 0.423 \\
\hline
\end{tabular}

\section{Factors associated with in-hospital mortality}

Older age; CVD history; coexistence of CVD and fQRS; having cancer; high SOFA score; and the existence of CRF, hypoalbuminemia, or lymphopenia were found to be associated with inhospital mortality in the univariate Cox regression analysis $(p<0.05)$. Although there was only borderline statistical significance noted, the CRP level on admission also showed an association with in-hospital mortality ( $\mathrm{p}=0.047$ ).

To determine the independent predictors of mortality, we performed a multivariate Cox regression analysis (enter method) by adopting variables that showed statistically significant associations in the univariate analysis. As an excellent correlation between CVD and the coexistence of CVD and fQRS ( $r=0.669$; $\mathrm{p}<0.001$ ) was determined, these variables were not included in the same regression analysis. Instead, we developed 2 separate multivariate analysis models (Table 3). In the multivariable Cox regression analyses for models 1 and 2, older age (HR: 1.022; $p=0.006$ and HR: $1.023 ; p=0.005$ ), cancer (HR: 1.912; $p=0.021$ and $H R=1.858 ; p=0.031$ ), high SOFA score (HR: 1.177; $p=0.003$ and HR: $1.215 ; p<0.001$ ), and increased CRP level on admission (HR: 1.003; $p=0.039$ and HR: $1.003 ; p=0.027$ ) were independent predictors of in-hospital mortality. Furthermore, in the model 1 analysis, CVD was not found to be an independent predictor $(p=0.078)$, whereas the coexistence of CVD and fQRS was determined to be an 


\begin{tabular}{|c|c|c|c|c|}
\hline Variables & All population ( $n=169$ ) & Survivors $(n=57)$ & Non-survivors (n=112) & $P$-value \\
\hline Fasting blood glucose, $\mathrm{mg} / \mathrm{dL}$ & $149 \pm 57$ & $144 \pm 58$ & $151 \pm 56$ & 0.466 \\
\hline WBC, 103/uL, median, (IOR) & $7.8(5.3-11.3)$ & $7.3(4.9-10.5)$ & $8(5.5-11.6)$ & 0.131 \\
\hline Neutrophil, 103/uL, median, (IQR) & $5.7(3.8-9.4)$ & $5.2(3.0-8.3)$ & $6.3(4.0-10.1)$ & 0.039 \\
\hline Hemoglobin, $g / L$ & $12 \pm 2.2$ & $12.7 \pm 1.6$ & $11.9 \pm 2.4$ & 0.015 \\
\hline Platelet, 103/uL & $231 \pm 91$ & $225 \pm 93$ & $233 \pm 89$ & 0.556 \\
\hline \multicolumn{5}{|l|}{ D-dimer, $\mu \mathrm{g} \mathrm{FEU/mL,} \mathrm{median,} \mathrm{(IQR)}$} \\
\hline Admission & $0.8(0.4-2.0)$ & $0.4(0.2-0.9)$ & $1.0(0.6-2.4)$ & 0.003 \\
\hline Admission & $100(45-175)$ & $79(19-171)$ & $105(60-179)$ & 0.006 \\
\hline Peak & $256(192-350)$ & $196(129-257)$ & 277 (209-359) & $<0.001$ \\
\hline Albumin, $\mathrm{g} / \mathrm{dL}$ & $3.3 \pm 0.5$ & $3.6 \pm 0.5$ & $3.1 \pm 0.4$ & $<0.001$ \\
\hline \multicolumn{5}{|l|}{ NT-proBNP, pg/mL, median, (IOR) } \\
\hline Admission & $450(133-2070)$ & $77(29-258)$ & $875(273-4080)$ & $<0.001$ \\
\hline Peak & $900(291-4505)$ & $144(34-619)$ & $1920(748-7430)$ & $<0.001$ \\
\hline \multicolumn{5}{|l|}{ CK-MB, ng/mL, median, (IOR) } \\
\hline Admission & $3.1(1.6-5.9)$ & $2.5(1.4-3.8)$ & $3.9(1.8-8)$ & 0.009 \\
\hline
\end{tabular}

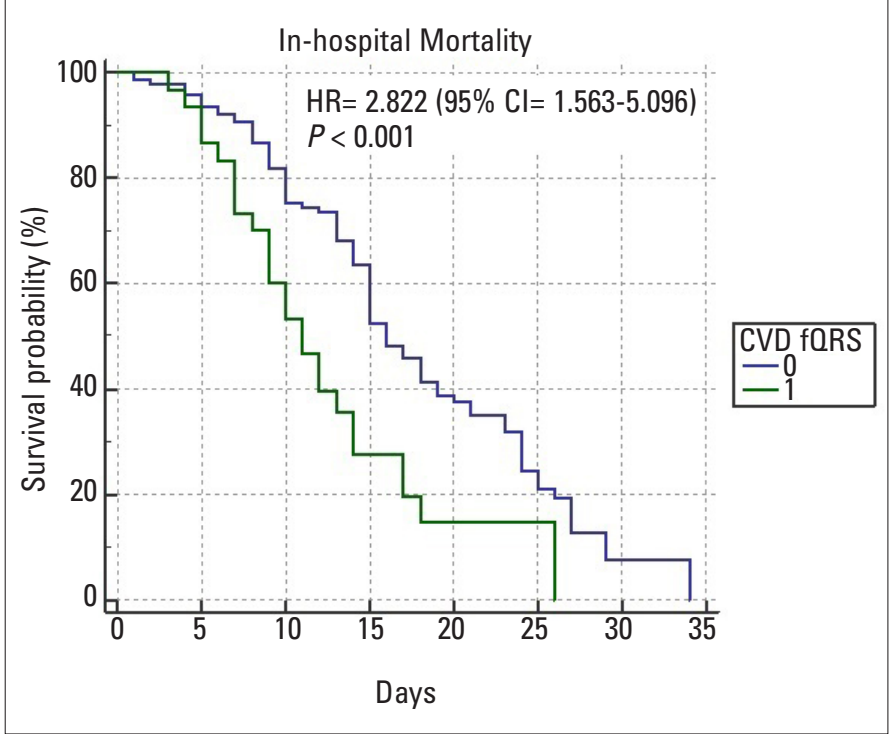

Figure 2. Kaplan-Meier plots of survival curves of patients with and without the coexistence of CVD and fQRS independent predictor of in-hospital death in the model 2 analysis (HR: 2.243; $p=0.003$ ). The association between in-hospital mortality and the coexistence of CVD and fQRS is depicted by Kaplan-Meier plots of survival curves in Figure 2.

\section{Discussion}

The main findings of this study are as follows; older age, CVD history, the coexistence of CVD and fQRS, having cancer, high SOFA score, CRF, hypoalbuminemia, and lymphopenia were significantly associated with in-hospital mortality among critically ill patients with COVID-19, but fQRS alone was not; and although older age, cancer, high SOFA score, increased CRP level at admission, and the coexistence of CVD and fQRS are independent predictors for in-hospital mortality, CVD alone is not predictive. To the best of our knowledge, this study is the first to evaluate the predictive value of fORS in determining the in-hospital mortality in individually critically ill patients with COVID-19. Of note, the results of this study reveal that the coexistence of fQRS 


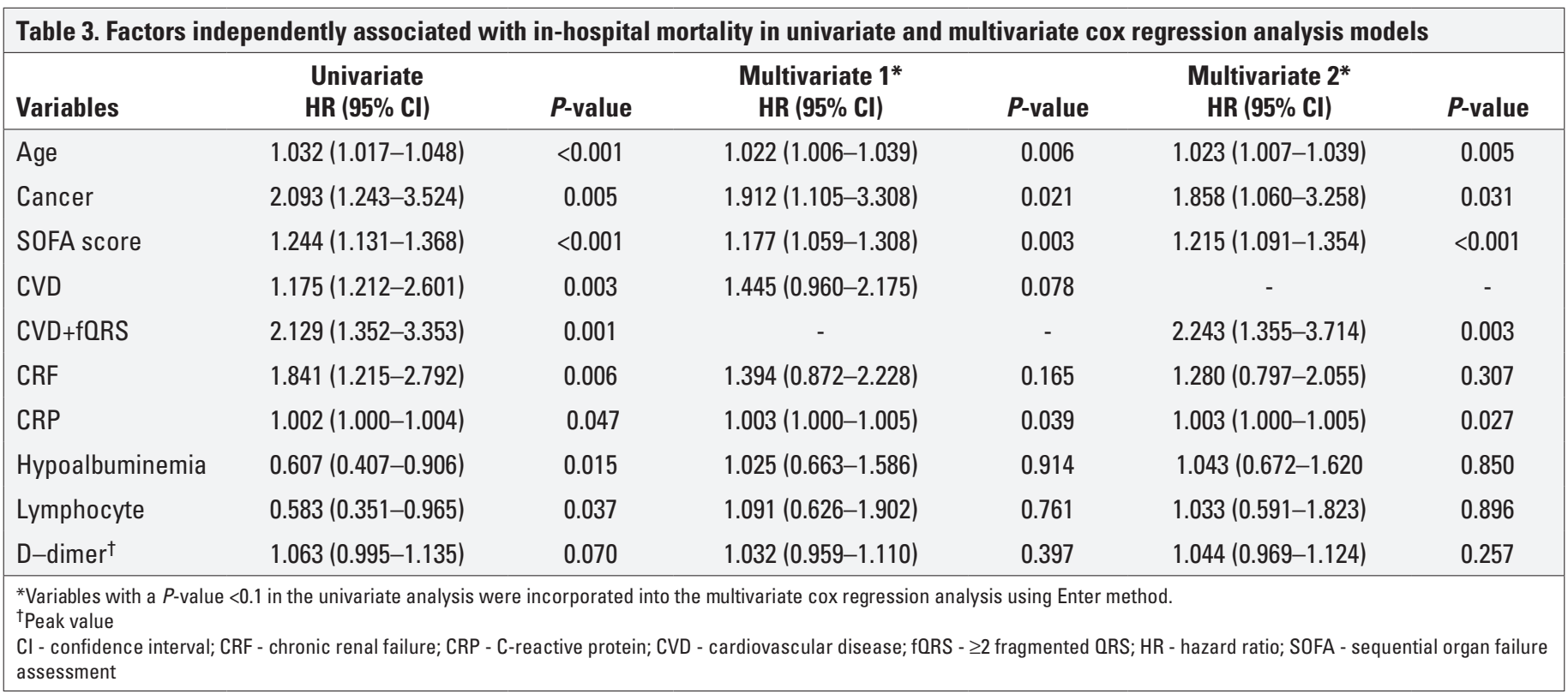

on baseline electrocardiogram and CVD acted as an important predictor of in-hospital mortality among critically ill patients with COVID-19. Even after adjusting for other risk factors in the univariate and multivariate logistic regression analyses, this relationship remained significant.

Though most people with COVID-19 have mild symptoms $(80.9 \%)$, some experience a severe $(13.8 \%)$ or critical $(4.7 \%)$ disease course. The proportion of critically ill patients with COVID19 in need of ICU hospitalization in China was reported to be $5 \%$ to $32 \%(20,21)$. Similar to the Chinese data, $257(22 \%)$ of 1,150 hospitalized patients with COVID-19 in the United States were reported to have COVID-19 of a critical severity (22). Consistent with the data above, in our study, the proportion of critically ill patients with COVID-19 was $16.3 \%$. Furthermore, the reported case fatality rate among critical cases varied from $16 \%$ to $78 \%$ according to different studies (23); in this study, the mortality rate was $66.3 \%$. As in our study, in a cohort of 3,844 patients in Lombardini, Italy, the mortality rate $(53.4 \%)$ was reported to be very high in critical patients with COVID-19 (24). Across countries, the major risk factors associated with death among critically ill patients with COVID-19 include older age; comorbidities (such as chronic cardiac and pulmonary conditions, hypertension, diabetes, chronic kidney disease); the development of ARDS, particularly severe ARDS; the need for mechanical ventilation; several abnormal hematological (such as severe lymphopenia, neutrophilia); and several increased biochemical parameters (such as CRP, D-dimer, and cTnl) (25). Similar to the data obtained so far, non-survivors had higher frequencies of comorbidities than survivors $(23,25,26)$. In terms of these risk factors, this study demonstrated that older age, malignancy, high SOFA score, and high CRP level at admission were independent predictors of in-hospital mortality as reported by several previous studies from China, the United States, and Italy $(20-22,27)$.
Previous studies have reported an association between underlying CVD and poor prognosis in patients with COVID-19; however, the minute details of this relationship still remain unclear (28). Although pre-existing CVD was more frequently observed in non-survivors in this study, it was not found to be a predictor of mortality as in the study of Shi et al. (29). Furthermore, in a meta-analysis, Aggarwal et al. (28) reported that pre-existing CVD was associated with the severity of COVID-19 and the overall risk of all-cause mortality, but these authors did not observe a significant relationship between a previous history of CVD and mortality in the context of severe COVID-19 disease.

fQRS is an electrocardiographic indicator of pre-existing myocardial fibrosis and has been shown to predict cardiac events in several cardiovascular conditions such as coronary artery disease, valvular heart disease, both ischemic and nonischemic cardiomyopathy, idiopathic dilated cardiomyopathy, and arrhythmogenic right ventricular dysplasia $(7-10,30,31)$. Pathophysiologically, fORS has been associated with disrupting the normally homogeneous depolarization process within the myocardium caused by electrically inactive fibrotic tissue, which is believed to be a substrate for arrhythmic events $(7,32)$. In this study, fQRS or CVD alone is not significantly associated with mortality; however, the coexistence of both is an independent predictor of mortality. This finding may be linked to a larger size of myocardial scars, a more depressed left ventricular systolic function, and intraventricular systolic dyssynchrony. Furthermore, although the respiratory tract is the most commonly affected system, COVID-19 has also been suggested to cause the development of various cardiovascular complications (e.g., myocardial damage, arrhythmias, and acute coronary syndrome), which can make a significant contribution to diseaserelated mortality $(1,20,33,34)$. Among these complications, acute cardiac injury is the most common complication in patients with COVID-19 and has been suggested to show a sig- 
nificant relationship with an increased risk of mortality (35). Several mechanisms such as cardiac physiologic stress, hypoxia, or direct myocardial injury have been proposed to be responsible for COVID-19 related cardiovascular complications. Systemic inflammation is one of these mechanisms and can lead to accelerated development of subclinical disorders or cause de novo cardiovascular damage. In addition, increased cardiometabolic demand related to the systemic infection coupled with hypoxia caused by acute respiratory illness can disrupt the myocardial oxygen demand-supply balance and lead to acute myocardial injury. In this study, we observed that patients with both fQRS and the coexistence of fQRS and CVD more frequently showed myocardial injury than those without these comorbidities. This study also demonstrated that non-survivors experienced myocardial injury more often. Indeed, Guo et al. (36) suggested in their study that myocardial injury is associated with cardiac dysfunction and a fatal outcome of COVID-19; and, as seen in our study, the prognosis of patients with underlying CVD but without myocardial injury was relatively more favorable than those with myocardial injury. Authors suggested that this finding may be related to increased systemic inflammation accompanying COVID-19 $(29,36)$. This may be another reason for why the results of our study support the prognostic importance of the coexistence of fORS and CVD in determining the risk of COVID-19 related mortality in critical patients.

\section{Study limitations}

Our study had some limitations. First, it involved a retrospective, single-center with a small sample size; therefore, larger prospective studies remain necessary. Second, this study was conducted in the early period of the pandemic period; and at that time, there was no established algorithm for the diagnosis, treatment, and monitoring of patients with COVID-19. The indication for hospitalization, especially in patients with moderate illness, was based on the physician's discretion. As we believe that this situation is an obstacle to the homogeneity of the study population, our study included only critical patients with COVID19 who were admitted to the ICU. The inclusion of all hospitalized patients with COVID-19 in the study may support a more detailed assessment of the predictive accuracy of coexisting CVD and fQRS in determining the mortality. Third, our study excluded patients with bundle-branch block. Fourth, in the early period of the pandemic process, echocardiographic examination could not be performed in most of the patients owing to the inability to fully establish diagnosis, treatment, and monitoring algorithms; major changes in the working order of healthcare professionals; and technical deficiencies. Therefore, we did not have sufficient information about the left ventricular ejection fraction values of the patients and could not analyze them. Finally, the association between fQRS and myocardial fibrosis has not been validated using imaging modalities or histopathological examination. Therefore, our findings should be interpreted cautiously.

\section{Conclusion}

fQRS may be considered as a simple, cheap, and time-saving handy risk-stratification tool that could help physicians looking to improve patient prognoses and clinical outcomes by identifying high-risk individuals, especially among those with CVD.

Conflict of interest: None declared.

Peer-review: Externally peer-reviewed.

Author contributions: Concept - F.K., M.K., I.Ş., E.O.; Design - F.K., M.K.; Supervision - I.S.., E.O.; Fundings - E.O.; Materials - F.K., S.K., H.A., S.V.; Data collection \&/or processing - F.K., S.K., H.A., S.V.; Analysis \&/ or interpretation - F.K., M.K., F.N.T.Ç., D.K.; Literature search - F.K., S.V.; Writing - F.K., M.K., D.K.; Critical review - I.Ş., K.E., E.O.

\section{References}

1. Wang D, Hu B, Hu C, Zhu F, Liu X, Zhang J, et al. Clinical Characteristics of 138 Hospitalized Patients With 2019 Novel Coronavirus-Infected Pneumonia in Wuhan, China. JAMA 2020; 323: 1061-9. [Crossref]

2. Borges do Nascimento IJ, Cacic N, Abdulazeem HM, von Groote TC, Jayarajah U, Weerasekara I, et al. Novel Coronavirus Infection (COVID-19) in Humans: A Scoping Review and Meta-Analysis. J Clin Med 2020; 9: 941. [Crossref]

3. World Health Organization. Naming the Coronavirus Disease (COVID-2019) and the Virus That Causes It (accessed on 1 March 2020). Available from: URL: https://www.who.int/emergencies/diseases/novel-coronavirus-2019/ technical-guidance/naming-thecoronavirus-disease-(covid-2019)-and-the-virus-that-causes-it

4. Wu Z, McGoogan JM. Characteristics of and Important Lessons From the Coronavirus Disease 2019 (COVID-19) Outbreak in China: Summary of a Report of 72314 Cases From the Chinese Center for Disease Control and Prevention. JAMA 2020; 323: 1239-42. [Crossref]

5. Babapoor-Farrokhran S, Gill D, Walker J, Rasekhi RT, Bozorgnia B, Amanullah A. Myocardial injury and COVID-19: Possible mechanisms. Life Sci 2020; 253: 117723. [Crossref]

6. Tian Y, Zhang Y, Yan Q, Mao J, Dong J, Ma C, et al. Fragmented QRS complex in healthy adults: Prevalence, characteristics, mechanisms, and clinical implications. Int J Heart Rhythm 2017; 2: 34-9. [Crossref]

7. Brohet C. Fragmentation of the QRS complex: the latest electrocardiographic craze? Acta Cardiol 2019; 74: 185-7. [Crossref]

8. Das MK, Khan B, Jacob S, Kumar A, Mahenthiran J. Significance of a fragmented QRS complex versus a 0 wave in patients with coronary artery disease. Circulation 2006; 113: 2495-501. [Crossref]

9. Yuce M, Davutoglu V, Ozbala B, Ercan S, Kizilkan N, Akcay M, et al. Fragmented QRS is predictive of myocardial dysfunction, pulmonary hypertension and severity in mitral stenosis. Tohoku J Exp Med 2010; 220: 279-83. [Crossref]

10. Das MK, Maskoun W, Shen C, Michael MA, Suradi H, Desai M, et al. Fragmented QRS on twelve-lead electrocardiogram predicts arrhythmic events in patients with ischemic and nonischemic cardiomyopathy. Heart Rhythm 2010; 7: 74-80. [Crossref]

11. Eyuboglu M, Karabag Y, Karakoyun S, Senarslan O, Tanriverdi Z, Akdeniz B. Usefulness of fragmented QRS in hypertensive patients 
in the absence of left ventricular hypertrophy. J Clin Hypertens (Greenwich) 2017; 19: 861-5. [Crossref]

12. Matsushita K, Ding N, Kou M, Hu X, Chen M, Gao Y, et al. The Relationship of COVID-19 Severity with Cardiovascular Disease and Its Traditional Risk Factors: A Systematic Review and MetaAnalysis. Glob Heart 2020; 15: 64. [Crossref]

13. Thomas H, Diamond J, Vieco A, Chaudhuri S, Shinnar E, Cromer S, et al. Global Atlas of Cardiovascular Disease 2000-2016: The Path to Prevention and Control. Glob Heart 2018; 13: 143-63. [Crossref]

14. Pranata R, Huang I, Lim MA, Wahjoepramono EJ, July J. Impact of cerebrovascular and cardiovascular diseases on mortality and severity of COVID-19-systematic review, meta-analysis, and metaregression. J Stroke Cerebrovasc Dis 2020; 29: 104949. [Crossref]

15. Zhao JY, Yan JY, Qu JM. Interpretations of "Diagnosis and Treatment Protocol for Novel Coronavirus Pneumonia (Trial Version 7)". Chin Med J (Engl) 2020; 133: 1347-9. [Crossref]

16. World Health Organization. Clinical management of severe acute respiratory infection when novel coronavirus ( $\mathrm{nCoV}$ ) infection is suspected (Jan 11, 2020). Available from: URL: https://www.who.int/ publications-detail/clinical-management-ofsevere-acute-respiratory-infection-when-novel-coronavirus-(ncov)- infection-is-suspected.

17. Thygesen K, Alpert JS, Jaffe AS, Chaitman BR, Bax JJ, Morrow DA, et al.; Executive Group on behalf of the Joint European Society of Cardiology (ESC)/American College of Cardiology (ACC)/American Heart Association (AHA)/World Heart Federation (WHF) Task Force for the Universal Definition of Myocardial Infarction. Fourth Universal Definition of Myocardial Infarction (2018). J Am Coll Cardiol 2018; 72: 2231-64. [Crossref]

18. American College of Cardiology/American Heart Association Task Force on Clinical Data Standards (ACC/AHA/HRS Writing Committee to Develop Data Standards on Electrophysiology), Buxton AE, Calkins H, Callans DJ, DiMarco JP, Fisher JD, et al. ACC/ AHA/HRS 2006 key data elements and definitions for electrophysiological studies and procedures: a report of the American College of Cardiology/American Heart Association Task Force on Clinical Data Standards (ACC/AHA/HRS Writing Committee to Develop Data Standards on Electrophysiology). Circulation 2006; 114: 253470. [Crossref]

19. Khwaja A. KDIGO clinical practice guidelines for acute kidney injury. Nephron Clin Pract 2012; 120: c179-84. [Crossref]

20. Guan WJ, Ni ZY, Hu Y, Liang WH, Ou CQ, He JX, et al.; China Medical Treatment Expert Group for Covid-19. Clinical Characteristics of Coronavirus Disease 2019 in China. N Engl J Med 2020; 382: 1708-20. [Crossref]

21. Huang C, Wang Y, Li X, Ren L, Zhao J, Hu Y, et al. Clinical features of patients infected with 2019 novel coronavirus in Wuhan, China. Lancet 2020; 395: 497-506. [Crossref]

22. Cummings MJ, Baldwin MR, Abrams D, Jacobson SD, Meyer BJ, Balough EM, et al. Epidemiology, clinical course, and outcomes of critically ill adults with COVID-19 in New York City: a prospective cohort study. Lancet 2020; 395: 1763-70. [Crossref]
23. Halacli B, Kaya A, Topeli A. Critically-ill COVID-19 patient. Turk J Med Sci 2020; 50 (SI-1): 585-91. [Crossref]

24. Grasselli G, Greco M, Zanella A, Albano G, Antonelli M, Bellani G, et al.; COVID-19 Lombardy ICU Network. Risk Factors Associated With Mortality Among Patients With COVID-19 in Intensive Care Units in Lombardy, Italy. JAMA Intern Med 2020; 180: 1345-55. [Crossref]

25. Aly MH, Rahman SS, Ahmed WA, Alghamedi MH, Al Shehri AA, Alkalkami AM, et al. Indicators of Critical Illness and Predictors of Mortality in COVID-19 Patients. Infect Drug Resist 2020; 13: 19952000. [Crossref]

26. Parohan M, Yaghoubi S, Seraji A, Javanbakht MH, Sarraf P, Djalali $M$. Risk factors for mortality in patients with Coronavirus disease 2019 (COVID-19) infection: a systematic review and meta-analysis of observational studies. Aging Male 2020; 23: 1416-24. [Crossref]

27. Grasselli G, Zangrillo A, Zanella A, Antonelli M, Cabrini L, Castelli A, et al.; COVID-19 Lombardy ICU Network. Baseline Characteristics and Outcomes of 1591 Patients Infected With SARS-CoV-2 Admitted to ICUs of the Lombardy Region, Italy. JAMA 2020; 323: 1574-81. [Crossref]

28. Aggarwal G, Cheruiyot I, Aggarwal S, Wong J, Lippi G, Lavie CJ, et al. Association of Cardiovascular Disease With Coronavirus Disease 2019 (COVID-19) Severity: A Meta-Analysis. Curr Probl Cardiol 2020; 45: 100617. [Crossref]

29. Shi S, Qin M, Shen B, Cai Y, Liu T, Yang F, et al. Association of Cardiac Injury With Mortality in Hospitalized Patients With COVID19 in Wuhan, China. JAMA Cardiol 2020; 5: 802-10. [Crossref]

30. Sha J, Zhang S, Tang M, Chen K, Zhao X, Wang F. Fragmented QRS is associated with all-cause mortality and ventricular arrhythmias in patient with idiopathic dilated cardiomyopathy. Ann Noninvasive Electrocardiol 2011; 16: 270-5. [Crossref]

31. Canpolat U, Kabakçi G, Aytemir K, Dural M, Sahiner L, Yorgun H, et al. Fragmented ORS complex predicts the arrhythmic events in patients with arrhythmogenic right ventricular cardiomyopathy/ dysplasia. J Cardiovasc Electrophysiol 2013; 24: 1260-6. [Crossref]

32. Cheema A, Khalid A, Wimmer A, Bartone C, Chow T, Spertus JA, et al. Fragmented $\mathrm{QRS}$ and mortality risk in patients with left ventricular dysfunction. Circ Arrhythm Electrophysiol 2010; 3: 339-44. [Crossref]

33. Long B, Brady WJ, Koyfman A, Gottlieb M. Cardiovascular complications in COVID-19. Am J Emerg Med 2020; 38: 1504-7. [Crossref]

34. Nishiga M, Wang DW, Han Y, Lewis DB, Wu JC. COVID-19 and cardiovascular disease: from basic mechanisms to clinical perspectives. Nat Rev Cardiol 2020; 17: 543-58. [Crossref]

35. Shao MJ, Shang LX, Luo JY, Shi J, Zhao Y, Li XM, et al. Myocardial injury is associated with higher mortality in patients with coronavirus disease 2019: a meta-analysis. J Geriatr Cardiol 2020; 17: 224-8.

36. Guo T, Fan $\mathrm{Y}$, Chen M, Wu X, Zhang L, He T, et al. Cardiovascular Implications of Fatal Outcomes of Patients With Coronavirus Disease 2019 (COVID-19). JAMA Cardiol 2020; 5: 811-8. [Crossref] 